\title{
La estructura social en Haití y el movimiento de independencia en el siglo $x I X^{*}$
}

\section{Benoit Joachim}

La historiografia haitiana figura entre las más ricas del Continente y refleja la densidad histórica de Haití.

Se olvida a menudo $-y$ es bueno recordarlo, sobre todo ante la proximidad de los 500 años del encuentro de Europa con el mundo americano- que Haiti fue la primera etapa de esta colonización y el primer escenario de la resistencia indigena a la conquista. Además, en este territorio isleño se dio la más típica de las colonias de explotación, SaintDomingue, donde el colonialismo francés promovió, basado en la esclavitud, un extraordinario desarrollo productivo que sobresale en la América Latina del siglo XVIII. De esta matriz económico-social se desprendió la magnitud de la revolución haitiana de la independencia (1791-1804). La formación del Estado-Nación, su difícil supervivencia y desenvolvimiento en un mundo hostil dominado por el colonialismo y el racismo, se perfilan como verdaderos desafios al desarrollo del pais, hasta que la ocupación norteamericana (1915-1934), la más larga y sangrienta de las invasiones imperialistas en el continente, irrumpe dejando su huella, misma que perdura hasta la fecha.

Una trayectoria nacional tan compleja no podía dejar de generar grandes historiadores. Desde Thomas Madiou y Beaubrun Ardouin que escribieron durante las primeras décadas del siglo XIX sobre la guerra patria y los primeros años de la vida independiente, toda una escuela historiográfica se ha ido nutriendo en la caudalosa corriente de la vida y de las luchas de nuestro pueblo, creando obras de gran calado que han de figurar -como oportunamente lo programa el Instituto Dr. Mora - en una Antología Histórica de Haití.

Benoit Joachim pertenecia a esta tradición de historiadores. Formado en la Escuela Normal Superior de la Universidad de Haiti, enriqueció esta fuente original con el rigor de la ciencia histórica a partir del método marxista y de cursos de doctorado realizados en Francia bajo la dirección de Pierre Vilar. Colaborador del Centre National de la Recherche Scientifique, sus indagaciones en los Archivos Nacionales de Francia le permitieron descubrir importantes aspectos de las relaciones entre Haití y su ex metrópoli. Estas informaciones, asimiladas a partir de su sólida formación, le condujeron a novedosas interpretaciones y juiciosos aportes al conocimiento de las líneas de fuerza del desarrollo haitiano, tal como lo muestra el presente artículo.

Benoit, en el derrotero de un largo exilio, llegó a México en 1976, invitado por la Universidad Autónoma de Puebla a dirigir el Centro de Investigaciones Históricas y Sociales de esa Casa de Estudios. En 1979, un lamentable accidente en esa ciudad troncó su vida y su obra tan prometedoras. Su libro póstumo Les racines du sousdéveloppement en Haiti editado en Puerto Príncipe, recoge toda una herencia de historia e historiadores y renueva la visión del pasado proyectándola hacia el futuro de su pais y de América Latina.

Gérard Pierre-Charles

Es s dificil comprender la evolución social nacida en el siglo XIX con la revolución haitiana, si uno se inclina a estudiar exclusivamente las poblaciones de algunos centros urbanos embrionarios del litoral que ocupaban entonces el frente del escenario político de Haití. Sucede lo mismo con las actas legislativas de las instituciones gubernamentales y administrativas que no existían de hecho más que en el papel y no correspondían a la realidad.

Por lo contrario, la atención se debe llevar hacia las poblaciones del interior del país, sin detenerse mucho sobre los trazos superficiales o los destalles pintorescos de la vida diaria de la época con el pretexto de ori-

* Publicado en francés con el título "La structure sociale en Haïti et le mouvement d'indépendance au dix-huitième siècle" en Cahiers d'Histoire Mondiale, vol. XII, núm. 3, París, 1970, p. 452-465 (traducido por Norma Castro). 
ginalidad o de folclore. Importa sobre todo conocer y comprender la historia de los grupos sociales que combatieron entonces por la supresión del régimen anterior a 1791 y por la llegada de un orden nuevo que fuera más favorable al progreso social. De este proceso de gestación y, después, de consolidación del nuevo régimen, nacieron los grupos sociales cuya relación de fuerzas constituyó la base de esta evolución; es estudiando sus preocupaciones y sus características propias - y en particular el modo de apropiación y de explotación de los bienes heredados de la época colonial- como se podrá apreciar la amplitud del movimiento que dio origen a una nación haitiana. Los treinta y cinco años transcurridos entre la insurrección general de los esclavos (1791) y la publicación del código rural de 1826 (inmediatamente después de que Francia reconociera la independencia de su antigua colonia) fueron decisivos para la evolución posterior del pueblo haitiano. Entre tanto, el problema agrario seguia siendo fundamental; durante este periodo, fue resuelto en favor de una minoria privilegiada y en detrimento de la gran masa reducida a un nivel mínimo de existencia.

Una nueva clase dominante se formó enseguida para sustituir a los colonos y administradores franceses expulsados del pais. En el seno de esta clase se manifestaron oposiciones que frecuentemente revistieron carácter de violencia: ha quedado suficientemente demostrada la inconsistencia de la historiografía tradicional que atribuia a una oposición étnica (negros contra mulatos) las luchas que han marcado la historia de Haiti durante el periodo nacional.' La verdad reside en el hecho de que en las condiciones en que se desarrolló el proceso de la revolución haitiana, se originaron dos ramas rivales emanadas de una misma aristocracia: una de piel clara - que poseía una "experiencia" más antigua de la propiedad y la libertad - que representaba a burgueses del mismo origen étnico y socialmente solidarios; otra, dominada por negros que pretendian ser representantes de las masas negras sobre las cuales por otro lado, una y otra hacían pesar el mismo yugo con el mismo rigor.

La primera rama salió de las filas de la minoría de 28000 libertos, retoños de colonos blancos y esclalvals negras, existentes en la colonia en 1789. Proliferaron esencialmente en la parte meridional del país donde los colonos, llegados más tarde que los del Norte, parecen haber sido menos rigidos en lo que se refiere a las relaciones sexuales interraciales. En esta categoria de hombres libres se encontraban también algunos negros emancipados por sus amos, al momento de la revolución, estos libertos poseian la cuarta parte de las propiedades. Aunque lucharon por la igualdad de derechos con los blancos y fueron candidatos a suceder a los colonos, un buen número - propietarios de esclavos o enrolados en la policía contra los esclavos - no aspiraban a la abolición de la esclavitud; incluso algunos de ellos pensaron aliarse a los blancos para obstaculizar la libertad total y circunscribir la revolución a sus propias reivindicaciones. ${ }^{2}$ Pero humillados por los blancos y al acecho de los bienes de los colonos, abrazaron la causa de la República francesa y se apropiaron de los bienes de sus rivales que se habían comprometido con los ingleses y habían emigrado. Durante los años 1793-1796, en el

\footnotetext{
' L. Schiller Thébaud, Evolution de la Structure Agraire d Haiti de 1804 à nos jours, París. 1967

- Emile Nitu, Réclamation par les affranchis des droits civils et politiques, PuertoPrincipe, 1840. G. Debien, "Gens de couleur libres et colons de Saint-Domingue devant la Constituante" en Revue d'histoire de l'Amérique francaise, septiembre, 1950.
} 
Sur, donde dominaban, mantuvieron a los cultivadores en un estado de casi servidumbre. Sin embargo, su ascenso se vio frenado durante algunos años por el desarrollo fulgurante de una aristocracia de "nuevos libres". ${ }^{3}$

Hay que destacar que la otra parte de la clase dominante se componía de hombres salidos de la esclavitud. Si la insurrección general fue la senal de la libertad para todos, la revolución fue especialmente beneficiosa para una capa de esclavos situados en un escalón superior, si se les compara con los esclavos de las plantaciones: eran comendadores, "negros de talento" (es decir, aquéllos que habian aprendido un oficio), esclavos domésticos, etc.; un Toussaint (antiguo cochero), un Christophe (antiguo mozo de hotel) han salido de entre sus filas. En el curso de la lucha, consiguieron hacer valer su autoridad sobre la gran masa inorgánica, tanto por su capacidad, coraje, inteligencia, como por sus conocimientos. El ejército español de Santo Domingo les confirió grados y luego pasaron al servicio de la República francesa, que les concedió, como a todos los habitantes de la colonia, la calidad de ciudadanos. Se encontraron en primer plano gracias a las victorias obtenidas por sus tropas sobre generales y soldados ingleses y españoles y gracias también al apoyo decisivo que aportaron a los comisarios franceses amenazados por los colonos, maltratados después por los "antiguos libertos" de quienes se sospechaba que querían que SaintDomingue pasara a ser de su dominio exclusivo después de la derrota de los colonos. Promovidos a grandes administradores y grandes arrendatarios de las plantaciones abandonadas por los colonos emigrados, inspectores de los cultivos en las zonas de mando militar, formaron a su vez una verdadera aristocracia. Toussaint Louverture, su jefe supremo, dirigía por su cuenta varias plantaciones y poseía varias casas.

Incluso antes de conquistar la independencia, estas dos ramas de la aristocracia en formación chocaron en una guerra civil (junio de 1799julio de 1800) por la supremacia politica y la propiedad inmobiliaria. Los jefes de la primera rama, obligados a exiliarse después de la victoria militar de los louverturianos, se encontrarian, un año más tarde, en la armada expedicionaria francesa.

Pero poco después de la rendición de Toussaint Louverture, la deportación a Francia del jefe negro y de su antiguo adversario Rigaud, la amenaza de degradación de las dos ramas rivales -en que la deportación de sus dos jefes principales parecía ser el preludio- y, en fin, la tendencia al restablecimiento de la esclavitud (cuyos primeros síntomas ya habían provocado un nuevo levantamiento masivo) condujo a la unión nacional que hizo invitable la conquista de la independencia.

Desde el punto de vista de estos hombres, la independencia debía significar la sustitución definitiva de la dominación de los colonos y administradores franceses por la suya propia. Ahora bien, apenas habían descartado a los mencionados, cuando apareció un elemento de preocupación: Dessalines. Este hubiera podido ser el instrumento soñado para su política; conocido como discípulo de Toussaint que le había confiado la administración de 32 plantaciones, ${ }^{4}$ había sido designado general en jefe del ejército indígena, después gobernador vitalicio y por fin emperador. No impugnó el principio de la gran propiedad, pero

R. P. Gabon, Histoire d'Haiti, Puerto-Principe, 1930-1938, t. IV, p. 109. Paul Moral, Le passan haïtien, París, 1961, p. 15.

${ }^{4}$ Pamphile de Lacroix, Mémoires pour servir à l'histoire de la Révolution de SaintDomingue, Paris, 1819, t. 11, p. 47. 
persiguió a los falsos propietarios, anuló las ventas hechas por los colonos a partir de la guerra de independencia, revisó los títulos, supeditó la venta de los productos de los propietarios al pago a los cultivadores y al Estado de la parte que se les debia. ${ }^{5}$ La aristocracia del Sur llegó à temer ser exterminada, como lo habían sido los últimos colonos que quedaban en la isla. ${ }^{6}$ Algunas advertencias lanzadas por Dessalines eran inquietantes: "Antes de nuestro levantamiento - decía- los hombres de color, hijos de blancos, no recibian herencia de sus padres ¿Cómo es que después de haber expulsado a los colonos, sus hijos reclaman sus bienes? ¿Así pues los pobres negros cuyos padres están en Africa no tendrán nada?".7"¡He sabido que en el Sur no hay ni cien plantaciones embargadas y sin embargo he hecho desaparecer a todas las familias de colonos!"' "Igual que hago fusilar a los ladrones de pollos, de productos del campo y de bestias de carga, haré morir a quienes permitan, por complacencia, que se tome posesión de bienes del Estado." Las veleidades de reforma agraria que fueron atribuidas a quien hablaba así le condujeron a ser asesinado en una emboscada organizada por la coalición de propietarios de tierras amenazadas por la confiscación.

Eliminado Dessalines, la rivalidad de las dos aristocracias emergió a la superficie, cada una queriéndose arrogar la dirección del Estado. La escisión que siguió los destinó durante trece años a una evolución paralela: en el Norte, el rey Christophe concedió feudos a la nobleza hereditaria que habia creado; ${ }^{10}$ en la República dirigida por Pétion, los altos funcionarios y los oficiales superiores se atribuyeron las grandes y mejores plantaciones y, en el nivel de las comunas, los comandantes tomaron las tierras a su conveniencia, mientras que las capas inferiores recibieron, según su grado y función, parcelas formadas por cinco a treinta carreaux. ${ }^{11}$ De todos modos, con el suicidio del rey Christophe en 1820 y el fin de la escisión, los aristócratas del Norte y del Sur, negros y mulatos, tuvieron el privilegio común de poseer todas las grandes propiedades de tierras e inmobiliarias no pertenecientes al Estado; unos las poseian ya en la época colonial, otros las habían acaparado a pesar de las órdenes de Dessalines; otros más las habian recibido como feudos o como "donación nacional" cuando las distribuciones efectuadas por Christophe y Pétion. Un viajero jamaiquino, Richard Hill, que visitó el campo haitiano entre 1830 y 1831 , nos ha dejado numerosas informaciones sobre las grandes propiedades y sus propietarios. ${ }^{12}$

\footnotetext{
5 Maurice Nau y Nemours Telhomme, Code domanial, Puerto-Príncipe, 1930. Bando del 7 de febrero de 1804. Bando del ministro de Finanzas del 24 de julio de 1805 . Decreto del 10. de septiembre de 1806.

- Véanse las recriminaciones contenidas en las proclamas de los insurgentes de los Cayos (13 de octubre de 1806) y del general Gérin (12 de octubre de 1806) y en el acta "Résistance à l'oppression". Listant de Pradines, Recueil général des Lois des Actes du gouvernement d'Haiti, Paris, 1865, t. I, p. 154 y ss.

7 Tomado de Thomas Madiou, Histoire d'Haiti, Puerto-Príncipe, 1847, t. 111, p. 220.

8 Beaubrun Ardouin, Etudes sur l'histoire d'Haït, Paris, 1853-1860, vol. XI, t. 6. p. 208.

9 Thomas Madiou, Histoire d'Haïti,op. cit., p. 220.

so Cf. Vergniaud Leconte, Henry Christophe dans l'histoire d'Haiti, París, 1931.

1 Nau y Telhomme, Code domanial, op. cit., Bando del 30 de diciembre de 1809. Ley del 20 de octubre de 1811. Ley del 20 de marzo de 1812 . Ley del 4 de noviembre de 1812 . Ley del 5 de marzo de 1814 . Leyes del 12 y 26 de abril de 1814 .

Véase Armand Thoby, "Nos Constitutions républicaines", Revue de la Société haittienne de législation, 2 de marzo de 1894 . Un carreau equivale a 1.13 hectáreas (N. del T.).

12 Cartas de Richard Hill, en Macaulay, Haiti ou Renseignements authentiques sur l'abolition de l'esclavage, Paris, 1835, p. 76 y ss.
} 
En esta época empezaba el comercio de importación y exportación: los mulatos se alejaban de los bienes raices para fundar casas de comercio en los puertos. Ingleses y norteamericanos se instalaban a su vez. Los franceses llegaron más tarde, ya reconocida la independencia haitiana por Carlos X. Los negociantes se enriquecieron rápidamente y sin gran esfuerzo. Hacia mediados del siglo $x I X$, se creaban las más grandes fortunas no sólo mediante la venta de mercancías extranjeras al público y por la exportación, sino, sobre todo, por los suministros al Estado, fuente de prebendas, así como por las especulaciones financieras en las que los negociantes ejercian al mismo tiempo el papel de "banqueros" y de "proveedores de fondos".

En los centros urbanos existían también, además de las capas privilegiadas, capas intermedias (pequeños empleados, pequeños funcionarios, instructores, artesanos, etc.) y capas populares (sirvientes, buhoneros, descargadores, comerciantes ambulantes, etc.). Las capas populares se incrementaban constantemente con la llegada de campesinos que desertaban del campo, pero que no encontraban empresas industriales capaces de emplearlos.

De todos modos, una aplastante mayoría de la población haitiana vivía en el campo y se dedicaba a la agricultura. Estaba compuesta por antiguos esclavos y descendientes de esclavos. ¿Qué lugar se les reservaba en el régimen de la tierra? ¿Cuál era su situación económica y social?

Cuando los insurrectos de 1791 rompieron las cadenas que los unían a sus amos, soñaron con cubrir inmediatamente, en plena libertad, su propia subsistencia y la de sus familias. Sin embargo, todas las medidas decretadas por las clases dirigentes -o en su nombre- después de la abolición de la esclavitud en 1793, no tendieron más que a mantener en las plantaciones (voluntariamente o por la fuerza) a los cultivadores recientemente liberados, a manera de asegurar la producción de los productos de exportación. ${ }^{13}$ Cierto que los cultivadores tenían el derecho de propiedad. Pero disposiciones legales o simplemente reglamentarias limitaban sus posibilidades de adquirir pequeñas propiedades susceptibles de convertirlos en poseedores o explotadores independientes de las grandes plantaciones. ${ }^{14}$

Escritores como Alexandre Bonneau, ${ }^{15}$ demasiado ansioso de demostrar que los dirigentes mulatos eran liberales o progresistas - en oposición a los dirigentes negros-, se han empeñado en escribir que con la distribución de tierras operada durante la presidencia de Pétion, los campesinos se hicieron "dueños absolutos de sí mismos". Según otros testimonios, por el contrario, al terminar esta distribución, más de dos tercios de las familias campesinas no eran propietarias. ${ }^{16}$ En la medida en que se aplicaron las leyes agrarias emitidas por Pétion y Christophe entre 1807 y 1819 se crearon algunos miles más de pequeños propietarios ${ }^{17}$ pero es difícil saber cuántos fueron exactamente.

No es menos cierto que, pequeños propietarios o sin tierra, la mayoría de los cultivadores haitianos estaban reducidos al estado de aparceros. Tomemos en todo lo que vale el testimonio siguiente, de Richard

1. Cf. P. Moral, Le paysan haitien, p. 13 y ss.

14 lbid.

is Alexandre Bonneau, Haiti, ses progrès, son avenir, París, 1862, p. 37-38.

François Dalencour, Précis méthodique d'histoire d'Haïti, Puerto-Principe, 1932.

16 John Candler, Brief Notices of Hayti, with its Conditions, Ressources and Prospect. Londres, 1842, p. 23-25.

17 R. Hill en Macaulay, Haiti ou Renseignements authentiques..., op. cit., p. 87, 90 y ss. 
Hill: "La clase de los campesinos negros puede asimilarse a los aparceros de épocas feudales o a colonos aparceros." 18 Sin embargo, prosigue Hill, en el sistema haitiano "el señor o su representante es el encargado de repartir cada grano de la cosecha con el aparcero y no el aparcero con el señor". Como veremos más adelante, el aparcero trabaja pero es el terrateniente ausentista o su administrador, quien organiza, en algunos casos, el reparto del producto. "Por añadidura, el contrato no tiene más que una duración limitada, al término de la cual puede ser disuelto por consentimiento mutuo de ambas partes." Este tipo de sociedad dejaba poco al campesino. En el valle de Cap, donde Hill observó especialmente el sistema que describe, "estos cultivadores, al término de los tres años de su contrato, no obtenían por sus labores más que lo estrictamente necesario para garantizar sus necesidades". ${ }^{19}$

'De manera general, el cultivador recibía la cuarta parte de la cosecha en compensación por su trabajo. Ya sea que poseyera un huerto suficiente para su plantio, ya sea que se le concediera un espacio de terreno para este efecto dentro de la plantación, en general es de este cultivo del que el campesino de los valles extraía la mayor parte de su ingreso. $\mathrm{Pa}$ rece que era a la inversa para el campesino que recolectaba el café en los cerros.

En cuanto a las diferentes leyes y reglamentos sobre el gobierno de las plantaciones es suficiente leerlos para comprobar que son códigos de servidumbre. ${ }^{20}$ Obligaban a los cultivadores a vivir permanentemente en las tierras en que estaban asignados, a no alejarse más de veinticuatro horas sin autorización especial y, en fin, a probar su regularidad en el trabajo por medio de tarjetas de jornada, semana o mes. Todavia más, en las tierras de los altos funcionarios y de los generales, los cultivadores trabajaban bajo la vigilancia de una guardia militar. "Muchas veces - escribe James Franklin-21 he visto a los cultivadores trabajar bajo el terror de la bayoneta y del sable y esto en las plantaciones de Boyer (el presidente). Vi lo mismo en las del secretario general Inginac, del coronel Lerebours, del general Gédéon, del general Magny y de muchos otros." Los palos llovían muchas veces sobre los recalcitrantes. De hecho, su suerte correspondía a una semiservidumbre.

Los privilegiados y la mayor parte de los visitantes extranjeros les acusaban de pereza, de ociosidad, de vagabundaje. Sin embargo, el conjunto de la nación vivía esencialmente del trabajo del campesino. Los productos de exportación que obtenían era el único medio verdadero de compra del país; los derechos de aduana, finalmente eran ellos quienes los sostenían, eran casi la única fuente financiera del Estado. Ei tesoro público no servia más que para retribuir a los funcionarios, en un pais sin industria, $y$ a enriquecer a los concesionarios. Mientras que los grandes terratenientes no lograban retener suficientes trabajadores en sus plantaciones ni poner a flote sus ingenios de azúcar de los valles, el sector cafetalero que predominaba en los cerros - donde se refugiaba una gran cantidad de pequeños campesinos, un tanto independientes-

18 Ibid., p. 87. Sobre la aparcería en Haití véase también: P. Moral, Le paysan haïtien, p. 36 .

19 Ibid., p. 148

20 Véase principalmente: Reglamento de Toussaint Louverture relativo a la agricultura del 20 vendimiario, año IX. Constitución de 1801, título VI, Arts. 14, 15, 16 y 17. Bando del 4 frimario, año X, Ley del 20 de abril de 1807. The Code Rural of Hayti, Londres, 1827.

21 James Franklin, The present State of Hayti, Londres, 1828, p. 333-335. 
registraba sensibles progresos. ${ }^{22}$ Así, hay que señalar que de 1818 a 1842, el porcentaje en las exportaciones de café se elevó de 23 a $37 / 38$ millones de libras anuales y todavia habria que agregar a estas cifras la cantidad incontrolable de lo exportado de contrabando o consumido por la población local.

Por otra parte el pequeño aparcero de los valles, más preocupado por lo cotidiano y por sus propias necesidades que el gran propietario interesado sobre todo en los productos comerciales, desarrolló en primer lugar la horticultura, a pesar de las severas penas con que el reglamento castigaba a quienes caían en esta "contravención". La mayor parte de los trabajadores rurales se dedicaban al corte del palo de tintura y de maderas finas, cuya exportación conoció, durante el periodo nacional, un desarrollo sin precedente.

Mantenidos en el analfabetismo, los campesinos no dejaron testimonios escritos sobre su situación ni, según parece, memorias de reivindicaciones. Digamos que testimoniaron y reivindicaron, y de una manera elocuente, por medio de sus movimientos de protesta y alzamientos. Encontramos desde 1794 en la correspondencia de Toussaint Louverture, los ecos, de su rechazo al nuevo sistema de servidumbre suavizada que se les quería imponer: "Por aquí se nos veja mucho, no se nos paga bien lo que nos toca de los productos que elaboramos, se nos fuerza a vender por nada nuestros pollos y puercos cuando vamos al mercado y si pretendemos quejarnos, nos hacen arrestar por la policía y nos meten en prisión sin comer, e incluso, para poder salir, tenemos que pagar." 23 De ahí los problemas, "los desórdenes", los boicots a las grandes "estancias azucareras, añileras, algodoneras..." manifestaciones que los visitantes extranjeros y los ideólogos de las clases dominantes haitianas relacionaban demasiado pronto a la pereza. La huida y el refugio en los bosques y montañas perdidas, que representaban la transferencia de la energía al corte del palo de tintura, eran otras tantas formas de condena a su situación... Frente a este régimen, el cimarronaje constituía la réplica constante de los cultivadores. En efecto, sabemos, entre otros por los recuerdos del general Bonnet, que los campesinos "que querían liberarse de la vigilancia" y de la "acción de la policía", es decir aquéllos que querian escapar de la semiservidumbre en las plantaciones de los grandes propietarios y grandes arrendatarios "se fueron a vivir al fondo de los bosques donde su existencia permaneció ignorada mucho tiempo". ${ }^{24}$ Aún más, de 1807 a 1820, campesinos armados formaron una especie de "república independiente" en las montañas de la Grande-Anse (península del sur); bajo la dirección de su jefe Goman, desafiaron el poder de la aristocracia durante trece años; al final, hubo que lanzar en su contra más de seis regimientos para arrasar la región y exterminarlos ${ }^{25}$ y no fue ésta la última lucha de ese tipo en esa zona y el resto del pais. ${ }^{26}$

${ }^{22}$ Cf. Wallez, Précis Historique des négotiations entre la France et Saint-Domingue, Paris, 1826 , p. 70.

${ }^{23}$ Gérard M. Laurent, Toussaint Louverture à travers sa correspondance (1794-1798), Madrid, 1953, p. 316. Véase tambièn p. 394 y 368.

${ }^{24}$ Edmond Bonnet, Souvenirs historiques de Guy-Joseph Bonnet, París, 1864, p. 337.

${ }^{25}$ Camille Large, "Goman et l'insurrection de la Grande-Anse", Revue de la Societé haitienne d'histoire et de géographie, XII, 36, enero 1940; Castonnet Desfossés, La perte d'une colonie: la révolution de Saint-Domingue, París, 1893, p. 361; J. C. Dorsainvil, Manuel d'histoire d'Haiti, Puerto-Príncipe, 1949, p. 173-175, 183-184.

${ }^{26}$ La historia rural haitiana del siglo XIX y principios del XX estará marcada por los 
¿Podemos apoyarnos en esta oposición entre las ramas de una misma aristocracia y en este antagonismo entre las clases sociales para afirmar que, en el curso del periodo que hemos escogido, la nación haitiana no estaba verdaderamente constituida? Sería desconocer que la unidad nacional implica contradicciones sociales.

Es cierto que la fuerza de esta unidad depende de la solidez de su base económica, pero también está en función del grado de comunidad de intereses, así como de los problemas que crean, de la evolución del pen: samiento, y de la capacidad de la o de las clases dominantes, para asegurar la cohesión del cuerpo en su totalidad. Ahora bien, en este punto se impone hacer ciertas observaciones sobre las condiciones del nacimiento y consolidación del conjunto socioeconómico haitiano, condiciones que están en el origen de su fuerza y de su debilidad a la vez y que fijan el carácter específico de esta nación.

1. Unos cuantos cientos de miles de hectáreas sembradas de caña, algodón, añil, etc., escaparon al deterioro de las tierras durante la etapa colonial. Los incendios y destrucciones que siguieron causaron la ruina de las plantaciones: de 793 plantaciones azucareras, 3150 añileras, 789 algodoneras, 3117 cafetaleras, 150 cacaoteras, 182 destilerías, etc., con que contaba la colonia en 1789 , escasos fueron los plantios e instalaciones que quedaron en buen estado después de los doce años de tempestad revolucionaria.

2. En su huida, los colonos llevaron consigo los capitales que estaban casi exclusivamente en sus manos o que podian obtener de los negociantes de los puertos franceses. ${ }^{27}$ Privaron así a la nación haitiana de los fondos necesarios para su reconstrucción. Había que reconstituir el capital para hacer frente a los extremadamente altos gastos de volver a poner en funcionamiento los ingenios azucareros y otras manufacturas. Mientras tanto, la baja en los precios del azúcar no animaba a los nuevos propietarios y arrendatarios a hacer los esfuerzos de inversiones necesarios... aun si hubieran tenido los medios. Por otra parte, se mostraron incapaces de promover las relaciones sociales adecuadas, de concebir los medios apropiados para la revalorización racional de las instalaciones agrícolas. Nosotros nos inclinamos a creer que las posibilidades de solución del problema surgido del rápido crecimiento de la economía del país fracasaron por causa de las malas relaciones sociales existentes en la base de todo lo que se refiere a la producción (por ejemplo su carácter retardativo) más que a insuficiencias técnicas, sin embargo reales. Si las relaciones sociales hubieran correspondido mejor a las necesidades y reivindicaciones profundas de la mano de obra, recién liberada, sin duda habrian permitido, en más o menos breve plazo, allanar las dificultades debidas a la fuga de los capitales coloniales. El resultado de este estado de cosas fue que, hacia 1830 , especialmente en la parte meridional del país "una gran cantidad de plantaciones" permanecían en el estado de abandono en que las dejó la revolución" 28 mientras que el cultivo de hortalizas en los huertos prosperaba.

movimientos de pequeños campesinos, denominados Piquets en el sur y Cacos en el norte.

${ }^{27}$ Sobre la suerte de los antiguos colonos de Saint-Domingue repartidos por América del Norte y las Antillas españolas e inglesas, véase G. Debien, Les colons de SaintDomingue réfugiés à Cuba (1795-1815), Paris, 1954; De Saint-Domingue à Cuba avec une famille de réfugiés: Les Tornezy (1800-1809), Puerto-Príncipe, 1964; "Réfugiés de SaintDomingue aux Etats-Unis; Correspondencia de O'Rouhcke", R.S.H.H.G., vol. 21, p. 7779, 1950; Cr. Eugène Aubin, En Haït, Paris, 1910, p. VII.

2t Richard Hill, en Macaulay, Haiti ou renseignements authentiques..., op. cit., p. 158. 
3. Como si no fuera suficiente la fuga de los fondos necesarios para la recuperación económica del país, la rama de la aristocracia que dirigia el Estado - veintidós años después de la proclamación de la independencia - consistió en pagar una indemnización de 150 millones de francos para reparar las pérdidas de los colonos y a reducir en un $50 \%$ los derechos aduanales en favor del comercio francés: ${ }^{29}$ eran condiciones impuestas por la Restauración para reconocer una independencia contra la que ella misma confesaba no poder hacer nada; veremos más adelante las contradicciones que debilitaban la posición de la oligarquia haitiana de entonces, en el plano regional, y que explican la aceptación de la Ordenanza de Carlos X en 1825.

4. Sin embargo, no era sólo la antigua metrópoli la que dejaba pasar un tiempo relativamente largo antes de reconocer juridicamente la existencia de la nación haitiana; por el hecho de que ésta era el producto de una revolución de esclavos, y de negros en contra de sus amos blancos - por consiguiente desconfiable para todas las naciones blancas - dicho de otro modo, por el conjunto de la sociedad internacional de la época, incluyendo las naciones que sacaban provecho de su comercio: Inglaterra que temía por su colonia vecina, Jamaica; Estados Unidos, donde se mantenia la esclavitud y que se opusieron, en 1826 , a que se admitiera a Haití en el Congreso Interamericano de Panamá reunido a iniciativa de Simón Bolívar, el mismo que encontró asilo y ayuda en Puerto Príncipe en su lucha contra el colonialismo español... Por tanto, la nueva nación se veía obligada a vivir replegada en sí misma, rehusando el derecho de propiedad inmobiliaria y de tierras a los blancos - aunque introduciendo excepciones de hecho en esta interdicción - e incómoda con su sostén militar.

5. ¿La nación haitiana en formación había encontrado al menos las luces necesarias para su progreso en la enseñanza pública? En el régimen colonial no era cuestión de alfabetizar a los esclavos. Los colonizadores temian, sin duda, que el menor despertar intelectual en aquéllos a quienes comparaban con bestias de carga podria dar lugar a peligrosas pretensiones de emancipación. El trabajador de Saint-Domingue debía saber estrictamente lo que le había de mantener más sojuzgado. Eran rarísimos los esclavos que, beneficiándose de circunstancias totalmente excepcionales, podían aprender a leer y a escribir. De este modo, si la sed de libertad produjo el levantamiento general y permitió la proclamación de la independencia, el deseo de conocimiento creó la pequeña cantidad de los que el escritor haitiano Jean Fouchard denominó "los cimarrones del silabario" ..$^{30}$ Uno de éstos, el viejo Vastey, antiguo liberto, "haitiano criado en la cima de las montañas, en medio de los bosques" como dice él mismo y que morirá siendo barón de la monarquía de Christophe a los 85 años, da testimonio del esfuerzo cumplido por sus semejantes en la búsqueda del conocimiento. "La imperiosa necesidad lo hizo todo - escribe- . La mayoría se instruyeron por medio de los libros. Conoci perfectamente a muchos que aprendieron a leer y a escribir solos, sin ayuda de maestros; caminaban con su libro en la mano interrogando a los que pasaban para saber si ellos también podían leer y explicarles tal signo o tal palabra... Yo mismo, que escribo esto, creía

29 A. Bonneau (Haîti, ses progrès, son avenir, op. cit., p. 70) evaluó el díficit que causó este privilegio al tesoro haitiano en 1.6 millones de francos anuales sobre un ingreso de 6 millones.

${ }^{30}$ Jean Fouchard, Les marrons du syllabaire, Puerto-Principe, 1959. 
que el mundo terminaba donde mi vista alcanzaba; mis ideas eran tan limitadas que las cosas más simples me eran inconcebibles; y todos mis compatriotas eran tan ignorantes como yo mismo o aún más si esto fuera posible." 31 En este sentido, como en los otros, los libertos estaban, en general, más favorecidos. Algunos tuvieron los medios para ir a Francia y, unos cuantos, para escogerla como patria. ${ }^{32}$

A partir de la independencia, se concibieron proyectos de educación nacional tanto en el Reino del Norte como en la República del Sur. ${ }^{33}$ Amigo de Wilberforce, con quien estuvo ligado a una campaña contra la trata de negros, feroz enemigo de la Francia imperial y posnapoleónica de quien se recelaba quería reconquistar Haití, el rey Christophe declaró obligatorio el inglés en la escuela que creó en Cap Henry ${ }^{34}$ y confió a dos ingleses la dirección de su Colegio Real. Por su parte, el presidente Pétion auspició la creación de una escuela lancasteriana (de moda incluso en París), fundó un pensionado para jovencitas, así como un liceo dirigido por un francés. Pero como sabemos, "la mayoría de los alumnos, al llegar al liceo, no sabian leer o leían muy mal; no hablaban nada de francés y, aunque dotados de una magnífica memoria y una brillante imaginación ninguno tenía ni el hábito ni el gusto del trabajo". ${ }^{35}$ ¿Es necesario precisar que los maestros escaseaban terriblemente? De la Academia Haitiana fundada en 1825 por el médico del presidente Boyer, Fournier Pestaye (antiguo liberto que residió en Haití desde 1823 hasta 1828 ) no subsistirá más que una escuela de medicina. En suma, la educación pública permaneció en estado embrionario. Pero una pequeña cantidad de doctos, la mayor parte autodidactas que gravitaban alrededor del poder, se consagraban a una literatura militante (incluso en forma de teatro y de poesía). Atacaban violentamente al colonialismo, a la esclavitud de los negros, a los enemigos de la rama de la aristocracia a la que pertenecían y de la cual ellos eran portavoces.

6. Una idea muy común era que la religión constituía una fuerza civilizadora y moralizadora por excelencia: el colonizador habia legado a la sociedad haitiana la versión católica del cristianismo. Pero al revés de lo que pasó en Canadá donde un clero jerarquizado, disciplinado, formó cuadros de alto valor espiritual, Haití fue el refugio de curas más o menos en ruptura con la fe cristiana y con la Iglesia a la que pretendian servir, verdaderos aventureros, mercaderes de sacramentos, por lo menos durante toda la primera mitad del siglo XIX.Cierto que un abate Grégoire, aureolado por su prestigio de defensor de la causa negra, ejerció, de lejos, un cierto patronazgo espiritual respecto a Haiti. ${ }^{36}$ Pero el espectáculo de curas intrigantes, incluso “desvergonzados”, of recido a los ojos de los haitianos, de ninguna manera contribuyó a la elevación moral de la nueva sociedad. Por lo demás, este cristianismo que se había impuesto un tanto en Saint-Domingue - porque la religión de la

31 Vastey, citado por Auguste Viatte, Histoire littéraire de l'Amérique française, tercera parte, I: "Haîti", p. 336-337.

${ }_{32}$ Viatte, Ibid., p. 334.

${ }^{33}$ Cf. Sténio Vincent y L. C. Lhérisson, La Législation de l'instruction Publique de la République d'Haïti (1804-1895), París, 1895.

34 "Cap-Français" en la época colonial. "Cap-Haïtien" desde la independencia. "CapHenry" durante la monarquía de Chistophe, de 1807 a 1820; Cf. (nota 10), Vergniaud Leconte, Henry Christophe..., op. cit, p. 318 y ss.

${ }_{35}$ Discurso del secretario general Inginac del 16 de diciembre de 1819, citado por Viatte, Histoire littéraire de l'A mérique française, op. cit., p. 333.

36 Publicó en París, en 1824, un libro sobre La liberté de conscience et de culte en Haïti. 
metrópoli y del amo debía ser también la de la colonia - no habia permanecido católica más que entre una delgada capa de privilegiados. Convertida bastante superficialmente, la gran masa había asimilado el catolicismo a sus creencias tradicionales, hasta el punto de convertirlo en algo irreconocible. La multiplicidad de ángeles y santos del catolicismo, como de las "loas" o divinidades secundarias de las creencias africanas, la complejidad de misterios y dogmas (Trinidad-UnidadRedención-Resurrección), el ceremonial, las prácticas del culto, todo ello favorecía una mezcla entre la antigua y la nueva creencia. De la veneración a los fetiches a la de las nuevas imágenes sagradas no habia más que un paso y fue dado de inmediato. Se estableció la confusión y, partiendo de ella, se formó un sincretismo de donde nació la religión popular del "vudú". ${ }^{37}$ La verdad es que la mentalidad haitiana había permanecido ampliamente abierta a lo irracional. Una confianza demasiado grande en el "buen Dios" ("bon Dieu bon") inclinará hacia el fatalismo y no desembocará generalmente en la búsqueda de descubrimientos - científicos o de otro tipo - ni en un esfuerzo creador cualquiera.

7. En todo caso, el pueblo haitiano, tal como estaba históricamente constituido en el momento de la independencia, tenía en sí mismo la suficiente energía para progresar de manera continuada y para desempeñar un papel importante en la evolución de la humanidad. ${ }^{38}$

A pesar de que la sociedad haitiana de las primeras dos décadas del siglo XIX estaba fundamentalmente dividida en dos clases sociales con intereses opuestos - la aristocracia y el campesinado-, ambas estaban determinadas a mantener la independencia nacional. Al aplicar la consigna institucional que dice: "al primer cañonazo de alarma, las ciudades desaparecen y la nación está en pie", toda potencia extranjera que intentara desviar el curso de la historia haitiana después de la liberación general - por ejemplo invadiendo el territorio nacional- podia esperar el enfrentamiento de un mar de fondo popular. Era enemigo de la independencia haitiana el que dijo en 1824 que, aparte de Haití, "ningún país, ningún pueblo da, por su naturaleza, una garantía tan poderosa al mantenimiento de un orden establecido". ${ }^{39}$

\section{Referencia Bibliográfica Complementaria}

Avalle, Tableau des productions des colonies françaises aux Antilles..., París, 1799.

Césaire, Aimé, Toussaint Louverture. La Révolution française et le problème colonial, $\mathrm{Pa}-$ ris, 1961; Révolution de la Martinique depuis le Ier. septembre 1790 jusqu'au 10 mars 1971, Bibliothèque Nationale, Lk 12.137; Cf. Mémoires de 1762 y 1769.

Charlevoix, P.F.X., Histoire de l'isle espagnole ou de Saint-Domingue, (según Mémoires manuscritas del padre J. B. Le Pres, jesuíta, misionero en Santo Dimingo y según documentos originales conservados en el Depósito de la Marina), París, 1730, 2 vols.

- citado por Candelon Rigaud, Dans les campagnes d'Haiti, Paris, 1929.

de Gastine, Civique, Histoire de la République d'Haîti ou Saint-Domingue; l'esclavage et les colons, París, 1819.

37 C. Alfred Metraux, Le vaudou haïtien, París, 1959; Véase del mismo autor: Haït, la terre, les hommes, les dieux, Neuchatel, 1957; Más cercano a la época que estudiamos, véase E. Aubin, En Haiti, op. cit., p. 40 y ss.

${ }^{38}$ Gaston-Martin, L'ère des négriers, París, 1931; G. Debien, Les origines des esclaves des Antilles, Dakar, 1964; Cf. Michelson P. Hyppolite, Les origines des variations du créole haittien; Suzanne Sylvain, Le créole haïtien: morphologie et syntaxe, Wetrereu, Bélgica, 1951.

${ }_{39}$ Fleurine de Lagarde, Indication du moyen de faire reconnaître lautorité du Roi de Saint-Domingue, París, 1824, p. 14. 
Debbash, Yvan, Couleur et liberté. Le jeu du critèré ethnique dans un ordre esclavagiste, Paris, 1967.

- "Le marronnage. Essai sur la désertion de l'esclave antillais"', L'Année Sociologique, 1961 y 1962.

Debien, G., L'esprit d'indépendance chez les colons de Saint-Domingue au XVIIIè siècle, 1947; Esprit colon et esprit d'autonomie à Saint-Domingue au X VIIIè siècle, 2o. ed., París, 1954.

Esmangart, Charles, Des colonies françaises et en particulier de l'isle de Saint-Domingue, París, año $X$.

d'Auberteuil, Hilliard, Considérations sur l'état présent de la colonie de Saint-Domingue, París, 1776-1777.

James, P.I.R., Les Jacobins noirs, (trad.), París, 1949-1950.

Justin, Placide, Histoire statistique et politique de l'île d'Haiti, Paris, 1826.

Las Casas, Dom Bartolomé de, Relations des voyages et des découvertes que les Espagnols ont faits dans les Indes Occidentales, Amsterdam, 1698.

Le Pelletier de Saint-Rémy, Saint-Domingue. Etude et solution nouvelle de la question haitienne, París, 1846.

Malenfant, Des colonies et particulièremente de celle de Saint-Domingue. Mémoire historique et politique, París, 1814 .

Manigat, Leslie F., La politique agraire du gouvernement d'Alexandre Pétion, Puerto Príncipe, 1962.

Métral, Antoine, Histoire de l'insurrection des esclaves dans le nord de Saint-Domingue, París, 1818.

Montesquieu, Esprit des Lois, libro XXI, cap. XXI.

de Saint-Méry, Moreau, Description de la partie française de Saint-Domingue, 1797.

Nau, Emile, Histoire des Caciqueś d'Haiti, (2a. ed.) Puerto-Principe, 1894.

Nemours, Auguste, Haiti et la Guerre d'indépendance américaine, Puerto-Principe, 1952.

Pauleus Sannon, H., Histoire de Toussanit-Louverture, Puerto-Principe, 1933, 3 vols.

Roussier, P., (ed.), Lettres du Général Leclerc, París, 1938.

Saint-Amand, M., Histoire des révolutions d'Haïti, París, 1860.

Saint-Rémy des Cayes, Mémoires de Toussaint-Louverture, écrits par lui-même, pouvant servir à l'histoire de sa vie, París, 1853.

Saintoyant, J., La colonisation française sous la Révolution, Paris, 1929.

de Vaissière, Pierre, Saint-Domingue, s. 1., 1909.

Comte de Villèle, Mémoires et correspondance du Comte de Villèle, Paris, 1888. 